\title{
PREPRINT
}

$$
\text { CONF. } 9605 / 88 \cdots 2
$$

Note: This is a preprint of a manuscript being prepared for publication. Contents of this paper should not be quoted or referred to without permission of the author(s).

\begin{tabular}{|}
\hline Submitted to Transactions of the Materials Research Society of Japan 1996. \\
\hline Paper presented at the 1996 Annual Meeting of the Materials Research Society of Japan, \\
Makuhari, Japan, May 23-24, 1996. \\
Symposium L-Transparent Conductive Materials: Principles and Applications
\end{tabular}

\section{Deposition of hetero-epitaxial $\mathrm{In}_{2} \mathrm{O}_{3}$ thin films by molecular beam epitexEIVED \\ N. Taga and M. Maekawa \\ JUN 261996 \\ Research Center, Asahi Glass Co., Ltd., Kanagawa-ku, Yokohama 221, Japan

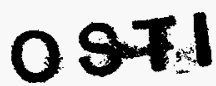 \\ Y. Shigesato and I. Yasui \\ Institute of Industrial Science, University of Tokyo, Minato-ku, Tokyo 106, Japan}

T. E. Haynes

Solid State Division, Oak Ridge National Laboratory, Oak Ridge, Tennessee 37831

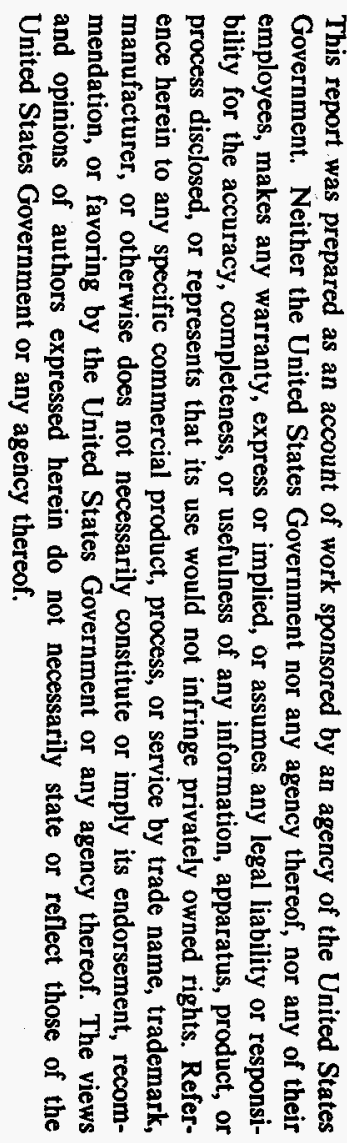

\begin{abstract}
"The submitted manuscript has been authored by a contractor of the US Government under contract No. DEAC05-96OR22464. Accordingly, the US Government retains a nonexclusive, royalty-free license to publish or reproduce the published form of this contribution, or allow others to do so, for US Government purposes."
\end{abstract}

Prepared in collaboration with

Oak Ridge National Laboratory

Oak Ridge, Tennessee 37831

Managed by

LOCKHEED MARTIN ENERGY RESEARCH CORP.

for the

U.S. DEPARTMENT OF ENERGY

under contract DE-AC05-960R22464.

May 1996

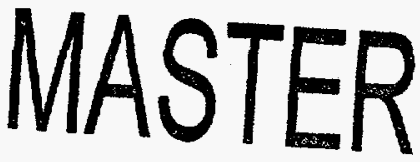




\section{DISCLAIMER}

Portions of this document may be illegible in electronic image products. Images are produced from the best available original document. 



\title{
Deposition of hetero-epitaxial $\ln _{2} 0_{3}$ thin films by molecular beam epitaxy
}

\author{
N. Taga ${ }^{1}$, M. Maekawa $^{1}$, Y. Shigesato $^{2}$, I. Yasui ${ }^{2}$ and T. E. Haynes ${ }^{3}$, \\ ${ }^{1}$ Research Center, Asahi Glass Co. Ltd., \\ 1150 Hazawa, Kanagawa-ku, Yokohama, 221, Japan \\ 2Institute of Industrial Science, University of Tokyo, \\ 7-22-1, Roppongi, Minato-ku, Tokyo, 106, Japan \\ ${ }^{3}$ Solid State Division, Oak Ridge National Laboratory, \\ 2008, Oak Ridge, Tennessee,37831, United States of America
}

Highly oriented thin film $\operatorname{In}_{2} \mathrm{O}_{3}$ was heteroepitaxially grown on optically polished (100) plane of single crystalline yttria stabilized zirconia (YSZ) substrate using Molecular Beam Epitaxy (MBE). Full-width at halfmaximum (FWHM) of X-ray rocking-curve showed $0.08^{\circ}$ for $\mathrm{In}_{2} \mathrm{O}_{3} 200 \mathrm{~nm}$ thick layers indicating that excellent uniformity orientation compared with the heteroepitaxially-grown $\operatorname{In}_{2} \mathrm{O}_{3}$ epitaxially deposited by the conventional methods such as electron-beam (e-beam) evaporation or sputtering method. The minimum yield $\left(\chi_{\text {min }}\right.$ ) of the MBE grown $\mathrm{In}_{2} \mathrm{O}_{3}$ film of Rutherford Backscattering Spectrometry (RBS) was also extremely small value $3.1 \%$, implying the very high crystallinity.

\section{INTRODUCTION}

Thin film of transparent conductive oxides have been widely used as transparent conductive electrodes in various optoelectronic applications due to its high transmissivity to visible light (more than $80-90 \%$ at $550 \mathrm{~nm}$ ) and its relatively low resistivity (lower than $4 \times 10^{-4} \Omega \mathrm{cm}$ ) $[1-3]$. Accordingly, there has been a great deal of work investigating their preparation processes and optimizing their properties[4-7]. Most of the efforts have been focused on the oxides of indium. tin and zinc although many authors have attempted to improve the electrical properties by adding small (typically a few percent) amounts of other elements as dopants ; for example $\operatorname{In}_{2} \mathrm{O}_{3}: \mathrm{Sn}(\mathrm{ITO})$ [8], $\mathrm{SnO}_{2}: \mathrm{F}[9]$, and $\mathrm{ZnO}: \mathrm{Al}$ or $\mathrm{Ga}[10]$.

The basic physics of all these systems are similar; the desirable properties result from the oxides being n-type, wide-gap semiconductor with an optical bandgap of between 3 and $4 \mathrm{eV}$ doped to give a (usually degenerate) electron gas in the conduction band. [11] Although to this extent the basic physics is understood, the knowledge of the relations between the defect state which scatter and/ or produce the free electrons and the electrical relations between the defect state which scatter and/or produce the free electrons and the electrical properties is very poor. In part this is because of the complex structure of unit cell of crystalline such as $\operatorname{In}_{2} \mathrm{O}_{3}$ (bixbyite Ia3) and the complicated nature of the conducting mechanisms in the polycrystalline structure.

Recently, well-oriented $\mathrm{In}_{2} \mathrm{O}_{3}$ films without large-angle boundaries have been fabricated using single-crystalline substrates of $\mathrm{MgO}$ or yttriastabilized zirconia (YSZ)[12-14]. Tarsa et al. reported on $\mathrm{In}_{2} \mathrm{O}_{3}$ films deposited by pulsed laser deposition that XRD rocking curve measurements revealed higher uniformity of surface-normal orientation of $\ln _{2} \mathrm{O}_{3}$ on $\mathrm{YSZ}$ (rocking curve FWHM $=0.29^{\circ}$, than the one on MgO (FWHM= $1.5^{\circ}$ ), because of the smaller lattice mismatch of $\sim 2 \%$ between $\operatorname{In}_{2} \mathrm{O}_{3}$ and $\mathrm{YSZ}\left(\mathrm{a}_{\mathrm{n} 2 \mathrm{O}}=1.0118 \mathrm{~nm}\right.$, $\left.2 \mathrm{a}_{Y S \mathrm{~T}}=1.026 \mathrm{~nm}\right)$ than $\mathrm{In}_{2} \mathrm{O}_{3}$ and $\mathrm{MgO}\left(2 \mathrm{a}_{\mathrm{MgO}}=\right.$ $0.842 \mathrm{~nm})[12]$.

Synthesis of heteroepitaxial grown $\mathrm{In}_{2} \mathrm{O}_{3}$ film with perfectly uniform orientation and very highly crystallinity should be important in order to investigate the relations between the defect state and the electrical properties, because it enables to use RBS technique for precisely analyses of the defect state. 
In this study the deposition of the heteroepitaxially grown $\mathrm{In}_{2} \mathrm{O}_{3}$ thin film on the YSZ single crystal with high uniform orientation and high crystallinity was carried out by MBE system and the characterizations of this film were also carried out. The difference in crystallinity between the heteroepitaxial film deposited by MBE system, by conventional e-beam evaporation and by sputtering technique was also studied to investigate the intricate difference of deposition techniques.

\section{EXPERIMENT}

Thin film $\mathrm{In}_{2} \mathrm{O}_{3}$ with thickness of about $2000 \AA$ were deposited on optically polished $(001)$ plane of $1 \mathrm{~mm}$-thick single crystalline yttria stabilized zirconia (IO/YSZ $(001)$ ) at $300^{\circ} \mathrm{C}$ using molecular beam epitaxy (MBE) system (ULVAC,MB633068). The MBE system was evacuated to the back pressure smaller than $6 \times 10^{-10}$ Torr and then $1.0 \mathrm{secm} \mathrm{O}_{2}$ gas was introduced into the system and blown on the substrate controlled using mass flow controller (STEC4200). Metal In was heated to $735^{\circ} \mathrm{C}$ in Knudsen Cell and evaporated onto the substrate. Before starting the deposition. the oxygen gas was introduced into the MBE system for about $5 \mathrm{hrs}$. to stabilize the oxidation of In source surface. After this operation, the deposition rate was precisely maintained at $6 \AA$ / min, about 100 times lower than the conventional e-beam evaporation, which was monitored by quartz crystal oscillator [ULVAC.CRTM-5000]. The deposition $\mathrm{In}_{2} \mathrm{O}_{3}$ films with the approximately same thickness were also deposited by a conventional e-beam evaporation with sintered $\mathrm{In}_{2} \mathrm{O}_{3}$ pellets. All these films had epitaxially grown was certified by standard $\theta / 2 \theta$ and pole figure XRD analyses.

The microstructure of the IO/YSZ(001) deposited by MBE and e-beam evaporation were analyzed by plane view SEM image using Hitachi $\$ 900$ FESEM. X-ray rocking curves were measured for precise evaluations on the uniformity of the crystalline grain orientation of the IO/YSZ1001) deposited by MBE system and e-beam evaporation. The crystallographic disorder of MBE deposited heteroepitaxial In $_{2} \mathrm{O}_{3}$ films was investigated by Rutherford Backscattering Spectrometry (RBS using a High Voltage Engineering Model AN-2500 Positive Ion Accelerator. The ion channeling was carried out using $2.0 \mathrm{MeV} \mathrm{He}^{2+}$ ion beam at a scattering angle of $160^{\circ}$.

\section{RESULTS}

Fig. 1 shows standard $\theta / 2 \theta$ (Fig. 1(a)) and polefigure (Fig.1(b),(c)) XRD peaks of the $10 / \mathrm{YSZ}$ (001) deposited by MBE system. These peaks show that the film had grown with excellent inplane crystalline orientation indicating heteroepitaxial growth. Figures $2(a, b)$ show the SEM surface images of the IO/YSZ(001) deposited by e-beam evaporation(Fig.2(a)) and MBE system(Fig.2(b)). The IO/YSZ(001) deposited by e-beam evaporation consisted of nonequilibrium shaped grains with size of 50-100 $\mathrm{nm}$. Whereas the $1 \mathrm{O} / \mathrm{YSZ}(001)$ deposited by MBE system consisted of in plane oriented, squareshaped grains indicating an excellent in-plane crystalline orientation of this film. Figures $3(a, b)$ show the results of $X$-ray rocking curve measurement for $10 / Y S Z(001)$ deposited by ebeam evaporation(Fig.3(a)) and by MBE deposition (Fig.3(b)). These results (rocking curve FWHM= $0.08^{\circ}$ for the film deposited by MBE system and $0.46^{\circ}$ for the film deposited by e-beam evaporation) indicate that the heteroepitaxial 10 / YSZ(001) deposited by MBE system has grown with much higher uniformity of crystalline orientation with the comparison of e-beam evaporated film.

An ion channeling spectrum from the heteroepitaxial $\mathrm{In}_{2} \mathrm{O}_{3}$ film deposited on $\mathrm{YSZ}(00$ () substrate by $\mathrm{MBE}$ deposition is shown in Fig.t.

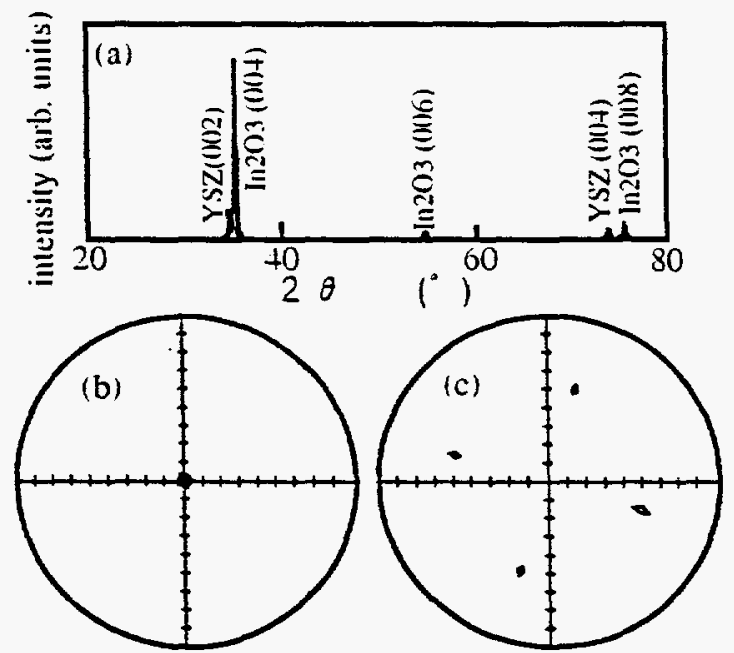

Fig. I Standard $\theta / 2 \theta$ (a), pole-figure for (400) diffraction (b) and (002) diffraction (c) of the IO/YSZ(001) deposited by MBE. 


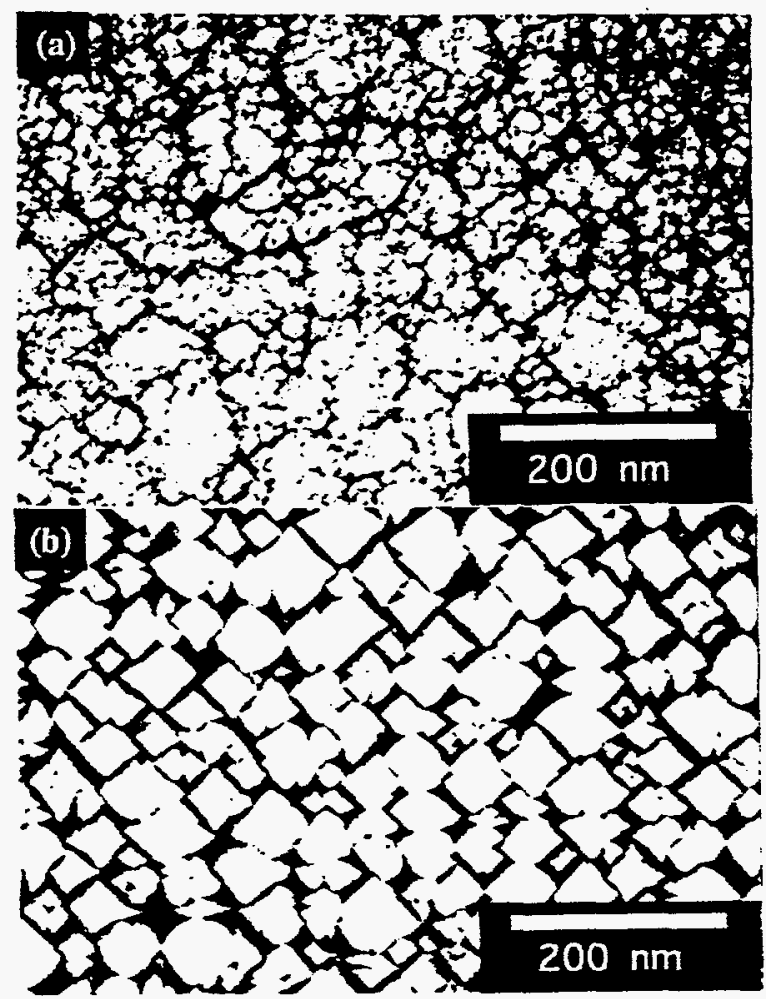

Fig. 2 SEM surface images of the IONYSZ(001) deposited by e-beam evaporation (a) and MBE system (b).

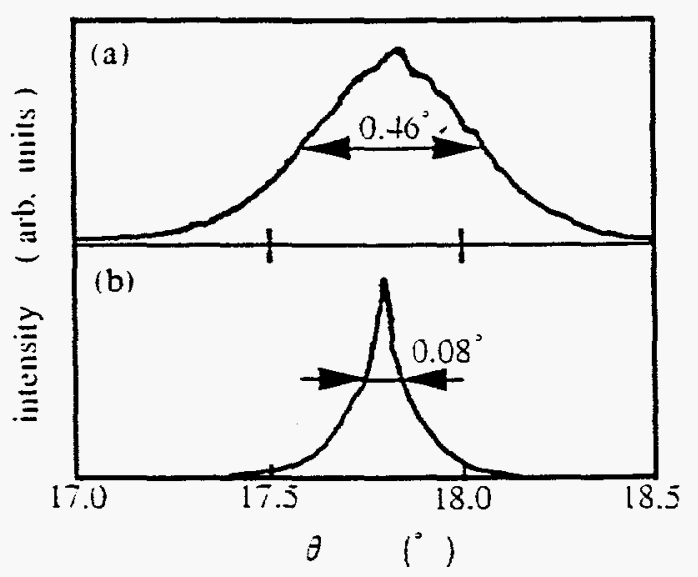

Fig. $3 \mathrm{X}$-ray rocking curve mesured on the $(004)$ $\mathrm{In}_{2} \mathrm{O}_{3}$ XRD peak of the film deposited by (a) e-beam evaporation and (b) MBE system.

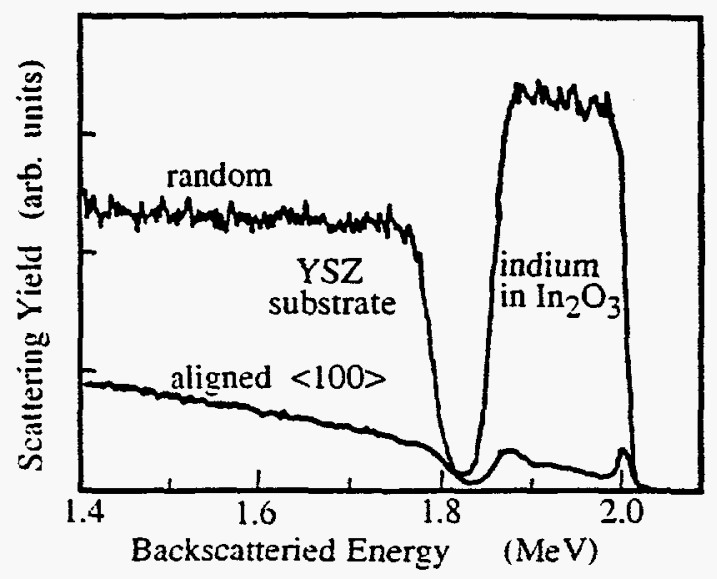

Fig. 4 Random and $<100\rangle$ aligned RBS spectra for IO/YSZ(001) film deposited by MBE system.

The minimum yield from the MBE deposited film is $3.1 \%$, which is better than that from the e-beam evaporated film $(4.1 \%)$. The difference in minimum yield is direct evidence that the MBE deposited film has fewer crystal imperfection.

\section{DISCUSSION}

Heteroepitaxial IO/YSZ(001) film deposited by MBE system showed both the much more uniform orientation and the higher crystallinity compared with tilms of approximately the same thickness deposited by a conventional e-beam evaporation, reasons for which must be worth discussing in order to evaluate the key factors for depositing the high quality epitaxial films.

We have reported the improvement in the uniformity of crystalline orientation and the crystallinity $\left(x_{\min }=4.5 \%\right)$ of the e-beam evaporated heteroepitaxial tin-doped indium oxide film (ITO/YSZ(001)) as compared with the sputtered ITO/YSZ $(001)\left(\mathrm{FWHM}=0.56^{\circ}, x_{\min }=8\right.$ $\%$ ), and concluded that the reason for this improvement was bombardment of the energetic particles in spurtering processes. [15]

In the sputtering processes two kinds of highenergy particles have been reported to bombard the growing film surface, i.e. (1) high energy neutrals $\left(A r^{0}\right)$ produced by neutralization of positive ions $\left(\mathrm{Ar}^{+}\right)$at the surface of the target [10] and (2) energetic negative ions $\left(\mathrm{O}^{-}\right)$accelerated in the cathode sheath to the substrate surface[ 17$]$. Since these bombardment of energetic particles during the film growth could perturb the growth surface and 
generate the secondary nucleation, the uniformity of crystalline orientation and the crystallinity should be disordered in the sputter deposition[18]. On the contrary, there are no high-energy particles in the e-beam evaporation process, which enable the heteroepitaxial growth with high uniformity of crystalline orientation and high crystallinity.

However, in the case of e-beam evaporation method where a source pellets is heated by electron beam irradiation, precisely control of the deposition rate is very difficult. The degree of oxidation of an oxide film is decided by the balance between deposition rate and reactive gas pressure, so the instability of deposition rate also causes the perturbation of the growing surface. On the other hand, in the MBE process, the deposition rate was about 100 times lower than e-beam evaporation and was precisely controlled. Accordingly, in the MBE system, the synthesis of perfectly stoichiometric crystal structure could be attained because of the regularity of supplying ratio and rate of $\mathrm{ln} / \mathrm{O}$ during film growth.

Moreover, it has been reported that the ITO films deposited on glass substrate at higher water partial pressure have a large amount of In-OH and $\mathrm{Sn}-\mathrm{O}-\mathrm{H}$ bonds, which is supposed to be exist at the interface berween the films and the substrates resulted from the increasing chemically adsorbed water on the glass surfaces[19]. In the extremely low back pressure process of the MBE system, there miglu be few amounts of $\mathrm{OH}$ bonds on substrate surface. which should enable the ideal heteroepitaxal growth on a clean substrate surface.

MBE process is considered to have such advantages compared with the other deposition techniques, so the film with extremely high uniform orientation and highly crystallinity could be deposited.

\section{CONCLUSIONS}

Heteroepitaxial growth of the $\mathrm{In}_{2} \mathrm{O}_{3}$ film was achieved on YSZ $(100)$ substrate using Molecular Beam Epitaxy, which enable to control the deposition rate precisely. FWHM value $0.08^{\circ}$ of $\mathrm{X}$-ray rocking curve have been obtained for this heteroepitaxial growth film. RBS channeling minimum yield $\left(x_{\min }\right)$ of the film was also quite small value of $3.1 \%$ implying that the film deposited by MBE has fewer crystal defects. The comparison with the results on the films using electron beam evaporation and sputtering technique revealed that $\mathrm{MBE}$ films had the perfectly uniform orientation and very highly crystallinity. The suppression of damages caused by the energetic particle bombardments during the film growth, the precise control of $\mathrm{In} / \mathrm{O}$ supplying ratio during the film growth and the deposition under ultra high vacuum were proved to be important key factors to deposit heteroepitaxial grown $\mathrm{In}_{2} \mathrm{O}_{3}$ film with extremely highly uniform orientation and high crystallinity.

\section{REFERENCE}

1. T. Kamimori, J. Nagai and M. Mizuhashi, Sol. Energy Mater. 16, 27 (1987).

2. H. Koh, K. Sawada, M. Ohgawara, T. Kuwata, M. Akatsuka and M. Matsuhiro, SID Dig. Tech. Rap. 19, 53 (1988).

3. Kobayashi, T. Ishida, Y. Nakato and

H. Tsubomura, J. Appl. Phys. 69, 1736 (1991).

4. P. Nath, R. F. Bunshah, B. M. Masel and O. M. Stuffsud, Thin Solid Films 226, 104 (1993).

5. Y. Shigesato, S. Tkaki and T. Haranoh, J. Appl. Phys. 71 (7), 3356 ( 1992 ).

6. S. Ray, R. Banerjee. N. Basu, A. K. Batabyal and A. K. Bama, J. Appl. Phys. 54, 3497 (1983).

7. S Ishibasi, Y. Higuchi, Y. Ota and K. Nakamura, J. Vac. Sci. Technol. A8, 1403 (1990).

8. Y. Shigesato and David C. Paine, Appl. Phys. Lett. 62, 11, 1268 (1993)

9. A. Fujisawa, T. Nishino and Y. Hamakawa, Jpn. J. Appl. Phys. 27, 4, 552 (1988).

10. T. Minami, H. Sato, H. Nanto and S. Takata, Jpn. J. Appl. Phys. 24, 10, L781 (1985).

11. Hamberg and C. G. Granquist, J. Appl. Phys. 60, R123 (1986)

12. E. J. Tarsa, J. H. English, and J. S. Speck, Appl. Phys. Lett. 64, 2332 (1993).

13. M. Kamei, T. Yagami, S. Takai, and Y. Shigesato, Appl. Phys. Lett. 62, 2332 (1993).

14. M. Kamei, Y. Shigesato, S. Takaki. Y.Hayashi, M. Sasaki and T. E. Haynes, Appl. Phys. Lert. 65, 546 (1994).

15. N. Taga, Y. Shigesato, I. Yasui, T. E. Haynes and M. Kamei, submitted to J. Appl. Phys..

16. I. Brodie, L. T. Lamont, Jr. and R. J. Jepsen, Phys. Rev. Lett. 21, 1224 (1968).

17. K. Tominaga, T. Yuasa, M. Kume and O. Tada, Jpn. J. Appl. Phys. 24, 944 (1985).

18. Y. Shigesato and David C. Paine, Thin Solid Films. 238. 44 ( 1994).

19. Y. Shigesato. Y. Hayashi, A. Masui and T. Haranou, Jpn. J. Appl. Phys. 30,4, 814 (1991). 